\title{
O processo de redemocratização e o novo padrão de proteção do direito à saúde no Brasil
}

The process of democratization and the new standard of protection of the right to health in Brazil

\section{Edith Maria Barbosa Ramos}

Doutora em Políticas Públicas. Professora Adjunta do Departamento de Direito e do Mestrado em Direito e Instituições do Sistema de Justiça da Universidade Federal do Maranhão. Professora e Pesquisadora da Universidade CEUMA. Coordenadora do Núcleo de Estudos em Direito Sanitário (NEDISA). São Luís, Brasil.

\section{Amanda Silva Madureira}

Mestre em Direito. Professora da Universidade CEUMA. Pesquisadora do Núcleo de Estudos em Direito Sanitário da Universidade Federal do Maranhão (NEDISA). São Luís, Brasil.

\section{Jaqueline Prazeres de Sena}

Mestre em Direito. Professora Assistente do Curso de Direito da Universidade Federal do Maranhão. Pesquisadora do Núcleo de Estudos em Direito Sanitário da Universidade Federal do Maranhão (NEDISA). São Luís, Brasil.

Resumo: Objetiva-se apresentar elementos conceituais sobre o processo de redemocratização do Estado brasileiro e sobre as determinações da proteção social no Brasil, em especial, do direito à saúde, após a promulgação da Constituição Federal de 1988. Apontam-se os tópicos iniciais de uma discussão sobre os novos paradigmas da Seguridade Social, em oposição às ideias de caridade e filantropia afirmadas durante o período da Ditadura Militar. Mostra-se que a Constituição Federal de 1988 representou um marco decisivo para a formulação de políticas públicas universais na área da saúde, numa perspectiva de tutela e garantia de direitos.

Palavras-chave: Seguridade social; direito à saúde; democracia.

Keywords: Social security; right to health; democracy.

\section{Introdução}

Objetiva-se analisar o direito à saúde sob o prisma da Seguridade Social. Compreende-se, nesta perspectiva, que se faz necessário realizar uma digressão histórica, em especial, ao período da ditadura militar, com o objetivo de apresentar o 
processo de mudança do paradigma da saúde como caridade ou filantropia para a configuração do direito à saúde como elemento fundamental à ideia de cidadania. Procura-se destacar e evidenciar a Constituição Federal de 1988 como um marco no avanço democrático na formação histórica da sociedade brasileira. Verifica-se que a elaboração da CF/88 é resultado de uma Assembleia Nacional Constituinte evidenciada pela pluralidade e participação de diferentes atores sociais. Com efeito, direitos que anteriormente não eram assegurados pelo ordenamento jurídico brasileiro foram consagrados na referida Carta Política como direitos fundamentais.

Visa-se, ainda, compreender por que a Constituição Federal de 1988 foi a primeira Constituição brasileira a prever o direito à saúde como direito fundamental e compreender que seu processo de implementação depende da articulação entre políticas econômicas e sociais. Objetiva-se, por fim, demonstrar que a ideia de completo bem-estar (físico, social e mental) do povo está diretamente vinculada às opções dos governos e que a forma de alcançar as metas traçadas pela Constituição Federal e pelo Sistema Único de Saúde perpassa pelo processo de redemocratização da sociedade brasileira e pela efetiva participação popular nos espaços configurados constitucionalmente. É nesse contexto que se justifica a necessidade de aprofundar os estudos sobre o direito à saúde, como se pretende, mesmo que de forma inicial, destacando-se a necessidade de articulação das diferentes políticas sociais e a atuação imprescindível do poder público.

Adota-se como linha metodológica a crítico-dialética, a partir de uma vertente jurídico-histórico-sociológica, desenvolvida por raciocínios dialéticos, pois se entende que a compreensão da realidade não é estática, mas vinculada a um processo de interpretação constante das contradições e da luta dos contrários, num ininterrupto "devir".

O presente artigo está dividido em duas partes, o primeiro trata do contexto geral da seguridade social brasileira no período da Ditadura Militar, e o segundo aborda a construção histórica da saúde como direito fundamental social no Brasil. Por fim, conclui-se que indiscutivelmente, a Constituição Federal de 1988 representou um grande avanço no padrão de proteção social adotado no Brasil. As normas constitucionais projetaram e exigiram uma mudança de paradigma que saiu de um modelo meritocrático-particularista para um modelo institucional-redistributivo, ou seja, um caminho em direção a uma forma mais universalista e igualitária de organização da proteção social no país, em especial a proteção do direito à saúde. 


\section{Contexto geral da seguridade social no período da ditadura militar.}

A ditadura militar representou o aprofundamento de grandes problemas estruturais herdados das décadas anteriores, tais como alto grau de doenças infecciosas e parasitárias e elevadas taxas de morbidade e mortalidade infantil, como também da mortalidade em geral. No que diz respeito à questão social o período de 1964 a 1974 representou a utilização pelo Estado do binômio - repressão-assistência. Faleiros (2000) analisa esse fenômeno destacando que no contexto de perda das liberdades democráticas, de institucionalização e acirramento da censura, na efetivação de prisões e torturas às oposições, a estrutura militar esquadrinhou a adesão e legitimidade popular através da expansão e modernização de políticas sociais.

Durante esse período de autoritarismo do governo brasileiro a política de proteção social foi ampliada e burocratizada pela máquina estatal com o objetivo de alargar o poder de controle sobre a sociedade, bem como amenizar as tensões sociais e legitimar o regime de exceção. Outro elemento intrínseco a ampliação da seguridade social no período militar foi a acumulação do capital, obediente ao sistema capitalista internacional. Para Rizotti (1997, p. 6)

Sob essa ótica, podemos lançar luz ao sentido das mudanças introduzidas pelos governos militares na legislação social brasileira. Basicamente, estas mudanças estiveram direcionadas para fornecer respostas às reivindicações que moviam os movimentos populares de contestação ao regime, propondo, de um lado, a ampliação qualitativa dos benefícios existentes - como, por exemplo, a extensão de direito previdenciários a trabalhadores rurais e empregados domésticos - e de outro, uma expansão quantitativa dos serviços governamentais, que era apresentada ao público como solução para a universalização do acesso aos serviços de educação e, mais especialmente, de saúde e habitação. Não obstante a veiculação desta imagem, o objetivo real de tais medidas era a restrição da base social dos movimentos populares emergentes, e seu resultado concreto consistiu na centralização expressiva das políticas de desenvolvimento, no acirramento do controle de seus serviços pela burocracia governamental e no recrudescimento das práticas clientelistas antes minimizadas com o encerramento do populismo. Sob o manto de uma falsa neutralidade gerencial, as políticas sociais do período adquiririam um traço contundentemente tecnocrático e, amplamente burocratizado, encontrar-se-iam à mercê dos grupos e associações de interesses individuais e corporativos que gozavam de ascendência sobre as instâncias decisórias de governo.

O movimento de 1964 contou com o suporte da maioria da burguesia que defendia a internacionalização da economia e das finanças brasileiras, obstaculizada pela proposta populista de fortalecimento das empresas públicas do governo João 
Goulart. Além disso, destaque-se a preocupação em relação à proliferação do socialismo (e comunismo) no Mundo, e em especial, na América Latina, que colocava em risco a hegemonia do capitalismo norte-americano no período da guerra fria. Segundo Ibrahin (2011, p. 4),

\begin{abstract}
Sabe-se que o Estado do Bem-Estar Social surgiu mais como um contraponto necessário ao crescimento do comunismo, do que propriamente pela conscientização dos dirigentes mundiais pela importância da proteção social. A farta oferta de benefícios foi feita, frequentemente, de modo irresponsável e visando unicamente rivalizar com o Leste Europeu.
\end{abstract}

Com o golpe de 31 de março de 1964 e a instalação do regime militar (apoiado pelos Estados Unidos) houve o fortalecimento do Poder Executivo e o esvaziamento do Poder Legislativo, bem como a apatia do Poder Judiciário. Os atos institucionais (documentos normativos editados pelo Poder Executivo) limitaram as liberdades individuais e constitucionais.

Deve-se destacar, no entanto, que o regime militar de caráter ditatorial e repressivo, não poderia se sustentar por tanto tempo utilizando-se exclusivamente de forças policiais/armadas e de atos de exceção. Assim, o regime procurou por meio de algumas políticas sociais justificar sua atuação e promover a legitimação do governo. Além disso, o regime militar utilizou-se da tecnoburocracia para garantir poder.

Em 1966 ocorreu a unificação, uniformização e centralização da previdência social no Instituto Nacional de Previdência Social (INPS) e como consequência houve a exclusão definitiva dos trabalhadores dos setores de gestão da previdência social. $\mathrm{Na}$ verdade, construiu-se, a partir daí, a ideia que a previdência social é questão técnica e atuarial. Neste mesmo contexto, em 1967, a questão dos acidentes de trabalho é, também, deslocada para a gestão do INPS, mesmo contrariando interesse de seguradoras privadas.

Além disso, em 1971 foi criado o Fundo de Assistência ao Trabalhador Rural (Funrural), caracterizado pela ampliação da previdência para os trabalhadores rurais, estruturado em pequena taxação de produtos e pago mensalmente no valor irrisório de meio salário mínimo. Deve-se, no entanto, ressaltar que o Funrural tinha um caráter mais redistributivo, pois não estava fundado em contribuição dos trabalhadores. Por outro lado, precisa-se destacar que a cobertura previdenciária alcançou as empregadas domésticas (1972), os jogadores de futebol e os autônomos (1973), e os ambulantes (1978), além disso, em 1974 foi criada a Renda Mensal Vitalícia de meio salário mínimo para os idosos pobres que tivessem contribuído ao 
menos um ano para a previdência (Behring, Boschetti, 2008, p. 136). Segundo Polignano (1988, p.14)

(...) Em consequência da repressão e do desmantelamento de todas as organizações da população civil, não podendo contar com a voz e não querendo a participação organizada da sociedade civil, o regime militar ocupou-se de criar uma tecnocracia, constituída de profissionais civis retirados do seio da sociedade, e colocados sob a tutela do Estado, para repensar sob os dogmas e postulados do novo regime militar, a nova estrutura e organização dos serviços do Estado, os tecnobrurocracistas. Pessoas que realmente acreditavam estar fazendo o melhor, repensando a sociedade brasileira de acordo com dados e pressupostos teóricos, colocando como exemplo abstrato a participação da sociedade. Assim, que dentro do objetivo de buscar apoio e sustentação social, o governo se utiliza do sistema previdenciário. Visto que os IAP's eram limitados a determinadas categorias profissionais mais mobilizadas e organizadas política e economicamente, o governo militar procura garantir para todos os trabalhadores urbanos e os seus dependentes os benefícios da previdência social.

O processo de unificação previsto em 1960, como demonstrado, se consolidou em 1967 com a implantação do Instituto Nacional de Previdência Social ${ }^{1}$ (INPS), que reuniu as diferentes entidades de previdência social, quais sejam: os seis Institutos de Aposentadoria e Pensão² (IAP's), o Serviço de Assistência Médica e Domiciliar de Urgência (SAMDU) e a Superintendência dos Serviços de Reabilitação da Previdência Social.

Duas particularidades fundamentais que impuseram a unificação da Previdência Social (com a junção dos IAPs em 1966) podem ser expressas no aumento da interferência do Estado na sociedade e no afastamento dos trabalhadores da cena política. Nesta perspectiva, observa-se a exclusão popular da gestão da previdência (os trabalhadores tornaram-se meros financiadores da previdência).

\footnotetext{
${ }^{1}$ O Decreto-Lei no 72 , de 21/11/1966, criou o Instituto Nacional de Previdência Social (INPS), o qual constituía entidade da administração indireta da União, com personalidade jurídica de natureza autárquica e gozava, em toda sua plenitude, inclusive no que se refere a seus bens, serviços e ações, das regalias, privilégios e imunidades da União.

${ }^{2}$ IAPM - Instituto de Aposentadoria e Pensão da Marinha Mercante Nacional e classes anexas; IAPB Instituto de Aposentadoria e Pensão dos Bancários; IAPC - Instituto de Aposentadoria e Pensão dos Comerciários; IAPI - Instituto de Aposentadoria e Pensão dos Industriários; IAPETC - Instituto de Aposentadoria e Pensão dos Estivadores e Trabalhadores de Carga e o IAPFESP - Instituto de Aposentadoria e Pensão dos Ferroviários e Empregados em Serviços Públicos. (Decreto no 22.872, de 29/6/1933)
} 
O Instituto Nacional de Previdência Social (INPS), como mencionado, unificou todos os institutos existentes, exceto o IPASE ${ }^{3}$. Sendo assim, o INPS passou a ter a função de controlar, administrar e alocar recursos provenientes dos seguros relativos a acidentes de trabalho. Ademais, uniformizou todas as prestações de benefícios e serviços a todos os membros do mercado formal de trabalho urbano.

Com a criação do INPS todo trabalhador urbano com carteira assinada era automaticamente contribuinte e beneficiário, em consequência disso houve um grande volume de recursos financeiros capitalizados. O aumento da base de contribuição aliada ao crescimento econômico da década de 1970 (milagre econômico) e ao pequeno percentual de aposentadorias e pensões fez com que o sistema acumulasse um grande volume de recursos financeiros. A unificação do sistema de previdência exigiu que o governo incorporasse outros benefícios, em especial a assistência médica, já oferecida anteriormente por alguns IAP's, inclusive com serviços e hospitais próprios.

Com o aumento de contribuintes e beneficiários do INPS, o governo militar viuse incapaz de garantir assistência médica previdenciária à população, optou por direcionar os recursos públicos para a iniciativa privada (objetiva cooptar apoio dos setores fundamentais da economia nacional e internacional). Houve a formação de convênios e contratos com médicos e hospitais, pagos pelos fundos públicos, o que proporcionou a capitalização dos setores médico-hospitalares, o aumento do consumo de medicamentos e insumos médicos, formando um "complexo sistema médico-industrial".

O grau de complexidade do sistema alcançou tal amplitude que determinou a formação de um órgão específico para cuidar da administração e financiamento do setor de saúde pública, o Instituto Nacional de Assistência Médica da Previdência Social (INAMPS), em 1977². Segundo Bravo (2001, p.07), no âmbito da saúde pública a ditadura militar representou a medicalização da vida social. Na medida em que

\footnotetext{
${ }^{3}$ O IPASE (Instituto de Previdência e Assistência dos Servidores do Estado) não era um instituto de aposentadoria e pensão como os demais. Tinha organização diferenciada e direcionada a servidores públicos, sendo criado pelo Decreto-Lei no 288/38. Por esse motivo o IPASE não foi extinto à época da unificação dos institutos, mas somente em 1977 (art. 27 da Lei oㅜ 6.439/77).

${ }^{4}$ A Lei no 6.439/77 instituiu o SINPAS (Sistema Nacional de Previdência e Assistência Social), buscando a reorganização da previdência social. O SINPAS agregava as seguintes entidades: I Instituto Nacional de Previdência Social (INPS); II - Instituto Nacional de Assistência Médica e Previdência Social (INAMPS); III - Fundação Legião Brasileira de Assistência (LBA); IV - Fundação Nacional do Bem-Estar do Menor (FUNABEM); Empresa de Processamento de Dados da Previdência Social (DATAPREV); VI - Instituto de Administração Financeira da Previdência e Assistência Social -
} 
(...) O setor de saúde precisava assumir as características capitalistas, com a incorporação das modificações tecnológicas ocorridas no exterior. A saúde pública teve no período um declínio e a medicina previdenciária cresceu, principalmente após a reestruturação do setor, em 1966.

Para Bravo (2001, p. 7), a conjuntura política interna e internacional representou no país a incorporação de um modelo de proteção social baseado no fortalecimento do produtor privado, com as seguintes diretrizes: Ampliação da cobertura previdenciária de forma a abranger a maior parte da população urbana, inclusive, os trabalhadores rurais, empregados domésticos e trabalhadores autônomos; destaque à prática médica curativa, individual, assistencialista e especializada, bem como, articulação do poder estatal com os interesses do capital internacional (por meio das indústrias farmacêuticas e de equipamentos hospitalares); criação do complexo médico-industrial (que permitiu o processo de acumulação de capital de grandes empresas farmacêuticas e de equipamentos médicos de âmbito internacional); intervenção estatal na previdência, com destaque ao paradigma da lucratividade da prática médica do setor de saúde; organização da prática médica em submissão a expansão do capitalismo no Brasil.

Em 1974, o Governo Federal cria o Ministério da Previdência e Assistência Social, incorporando a Legião Brasileira de Assistência (LBA), a Fundação Nacional para o Bem-Estar do Menor (Funabem), a Central de Medicamentos (CEME) e a Empresa de Processamento de Dados da Previdência Social (Datapreve). Após ampla reforma administrativa esse sistema se transformou no Sistema Nacional de Assistência e Previdência Social (SINPAS), em 1977, que incluía, como mencionado o INPS, o INAMPS e o IAPAS, além das instituições acima referenciadas. Conforme entende Behring e Boschetti,

Nessa associação entre previdência, assistência e saúde, impôs-se uma forte medicalização da saúde, com ênfase no atendimento curativo, individual e especializado, em detrimento da saúde pública, em estreita relação com o incentivo à indústria de medicamentos e equipamentos médico-hospitalares, orientados pela lucratividade (Behring, Boschetti, 2008, p. 137).

Como a ditadura militar, no período de 1964 a 1974, não conseguiu garantir a legitimidade do sistema, precisou alterar em profundidade sua relação com a

(IAPAS); e VII - Central de Medicamentos (CEME). O SINPAS, o qual se submetia à orientação, à coordenação e ao controle do Ministério da Previdência e Assistência Social (MPAS), tinha a finalidade de integrar a concessão e manutenção de benefícios, a prestação de serviços, o custeio de atividades e programas e a gestão administrativa, financeira e patrimonial de seus componentes. 
sociedade civil. Assim, o regime desenvolveu novas formas de mediação entre a dominação autoritária e suas consequências sociais e econômicas. A política social da ditadura militar, no período entre 1974 a 1979, objetivou um maior enfrentamento da questão social, com a finalidade de amenizar as reivindicações e pressões sociais. Contudo com destaca Behring e Boschetti,

(...) no mesmo passo em que se impulsionavam políticas públicas mesmo restritas quanto ao acesso, como estratégia de busca de legitimidade, a ditadura militar abria espaços para saúde, a previdência e a educação privadas, configurando um sistema dual de acesso às políticas sociais: para quem pode e para quem não pode pagar. Essa é uma das principais heranças do regime militar para a política social que do Welfare State europeu. Outra herança é a de que, mesmo com uma ampliação dos acessos públicos e privados, milhões de pessoas permaneciam fora do complexo assistencialindustrial-tecnocrático-militar (Behring, Boschetti, 2008, p. 137).

A partir de 1974, tornam-se visíveis as primeiras fissuras e sinais de esgotamento do projeto tecnocrático e modernizador-conservador do regime, principalmente em razão dos impactos da economia internacional, o que restringiu o fluxo de capitais, mas também em decorrência dos limites internos do país (Behring, Boschetti, 2008, p. 137). Em outras palavras, podem ser destacadas duas circunstâncias fundamentais para a crise: a) a crise do capitalismo em âmbito internacional e b) a diminuição do fluxo de capital estrangeiro para mover a economia nacional, o que diminuiu o ritmo de crescimento do país e do mundo.

Nesse período há um acirramento da pobreza, o Brasil apresenta-se com um dos países com maiores índices de concentração de renda, a população passou a conviver com o desemprego e a falta de assistência, bem como com suas consequências, quais sejam: marginalidade, favelas, mortalidade infantil, doenças etc. O modelo de saúde previdenciário mostra-se insuficiente e deficiente. Para Polignano, as mazelas desse sistema podem ser expressas da seguinte forma:

- por ter priorizado a medicina curativa, o modelo proposto foi incapaz de solucionar os principais problemas de saúde coletiva, como as endemias, as epidemias, e os indicadores de saúde (mortalidade infantil, por exemplo);

- aumentos constantes dos custos de medicina curativa, centrada na atenção médico-hospitalar de complexidade crescente;

- diminuição do crescimento econômico com a respectiva repercussão na arrecadação do sistema previdenciário reduzindo as suas receitas;

- incapacidade do sistema em atender a uma população cada vez maior de marginalidade, que sem carteira assinada e contribuição previdenciária, se viam excluídos do sistema; 
- desvios de verba do sistema previdenciário para cobrir despesas de outros setores e para realização de obras por parte do governo federal;

- o não repasse pela União de recursos do tesouro nacional para o sistema previdenciário, visto ser esse tripartide (empregador, empregado e União) (Polignano, 1988, p. 17).

Com o objetivo de conter custos e combater fraudes o governo federal criou em 1981 o Conselho Consultivo de Administração da Saúde Previdenciária (CONASP) ligado ao INAMPS. O CONASP acabou por incorporar em seus recursos humanos técnicos ligados ao movimento sanitário, o que permitiu dar início um processo de ruptura do domínio burocrático previdenciário. O CONASP inicia um processo de fiscalização rigorosa na prestação de contas dos prestadores de serviço. Propõe a reversão gradual do modelo médico-assistencial através do aumento de produtividade do sistema, melhoria da qualidade da atenção, equalização dos serviços prestados as populações urbanas e rurais, eliminação da capacidade ociosa do setor público, dentre outras estratégias de melhoria da gestão pública em saúde.

Com o agravamento da crise financeira o sistema social, em especial de saúde, redescobre o setor público e a necessidade de se investir em seus órgãos que atuam com custo mais barato e atendem um maior número de pessoas. Em 1983 foi criado a AIS (Ações Integradas de Saúde), que para Polignano foi um projeto interministerial (Previdência-Saúde-Educação) que visava

(...) um novo modelo assistencial que incorporava o setor público, procurando integrar ações curativas-preventivas e educativas ao mesmo tempo. Assim, a Previdência passa a comprar e pagar serviços prestados por estados, municípios, hospitais filantrópicos, públicos e universitários. Este período coincidiu com o movimento de transição democrática, com eleição direta para governadores e vitória esmagadora de oposição em quase todos os estados nas eleições democráticas deste período (1982) (Polignano, 1988, p. 210).

Segundo Tavares (1993, p. 42), na década de 1980, ocorreu uma transformação produtiva, cujos benefícios ficaram extremamente concentrados nas economias de primeiro mundo, enquanto os custos foram pagos pela crise financeira do Estado com fortes impactos para a política social, pelos sindicatos e pelos países da periferia (Behring, Boschetti, 2008, p. 140).

Por fim, cabe destacar que na década de 1980 ocorreu a redefinição das regras do jogo político no Brasil, na perspectiva de retomada do Estado democrático de direito. O Movimento das Diretas Já (1985) e a posterior eleição de Tancredo Neves, com a posse de José Sarney, que marcaram o fim do regime militar, 
Anais dos III Congresso Iberoamericano de Direito Sanitário / II Congresso Brasileiro de Direito Sanitário promoveram a consolidação de diferentes movimentos sociais, em especial os de saúde. Os movimentos sociais de saúde ganharam notabilidade com a VIII Conferência Nacional de Saúde (1986) que consolidou as bases da Reforma Sanitária no Brasil e apresentou a proposição do Sistema Único e Descentralizado de Saúde (SUDS) e do conceito de saúde integral, relacionada às condições de vida e trabalho da população (Behring, Boschetti, 2008, p. 145). Todos esses acontecimentos são simultâneos a Assembleia Nacional Constituinte (1986) que culminaram com a promulgação da Constituição Federal de 1988.

\section{Construção histórica da saúde como direito fundamental social}

As atrocidades realizadas, não raro pelo próprio Estado, durante a Segunda Guerra Mundial puseram em xeque as condições da vida humana e a premente necessidade de garantia efetiva dos direitos humanos. A guerra fria, a experiência socialista e a consolidação da questão social, em especial na Europa, obrigaram os Estados (democráticos) a reconhecer os direitos sociais como direitos humanos fundamentais.

O movimento de configuração positiva dos direitos sociais iniciou-se no âmbito da Organização das Nações Unidas, que já na Declaração Universal de Direitos Humanos de 1948 estabeleceu um rol extenso de dispositivos consagradores dos direitos sociais. Deve-se ainda destacar, em âmbito internacional, a criação de órgãos especiais para a garantia de direitos humanos essenciais. É o caso da saúde, que reconhecida como direito humano fundamental, passou a ser objeto da Organização Mundial de Saúde (OMS), órgão vinculado a ONU, que no seu preâmbulo conceitua saúde como da seguinte forma: saúde é o completo bem-estar físico, mental e social e não apenas a ausência de doenças e outros agravos.

Os ordenamentos jurídicos dos Estados europeus, após o fim da segunda grande guerra do século $\mathrm{XX}$, afirmaram constitucionalmente o direito à saúde. Algumas delas relacionam o direito à saúde à seguridade social, tais como: a Constituição Italiana de 1947, a qual protege a saúde como direito fundamental do indivíduo e interesse da coletividade e garante tratamento gratuito aos indigentes; a Constituição Portuguesa de 1976, com posteriores revisões, que assegura a direito à proteção da saúde e o dever do Estado de a defender e promover e a Constituição espanhola que reconhece o direito à proteção da saúde. (Dallari, 1995, p. 23). O século XX sedimentou o ideário de o direito à saúde está vinculado à proteção social 
Anais dos III Congresso Iberoamericano de Direito Sanitário / II Congresso Brasileiro de Direito Sanitário

em que o Estado tem o dever sanitário de prevenção e reparação da saúde, daí Dallari (2005, p.25) afirmar que

No início do século XX encontra instaurada a proteção sanitária como política de governo. E são hierarquizadas três formas, hoje clássicas de prevenção: a primária, que se preocupa com a eliminação das causas de condições de aparecimento das doenças, agindo sobre o ambiente (segurança nas estradas, saneamento básico, por exemplo) ou sobre o comportamento individual (exercício e dieta, por exemplo); a secundária ou prevenção específica, que busca impedir o aparecimento de doença determinada, por meio da vacinação, dos controles de saúde, da despistagem; e a terciária, que visa limitar a prevalência de incapacidades crônicas ou de recidivas (Leavell e Clark, 1976). O Estado do bem-estar social da segunda metade do século XX reforça a lógica econômica, especialmente em decorrência da evidente interdependência entre as condições de saúde e de trabalho, responsabilizando-se pela implementação da prevenção sanitária.

Instituem-se, então, os sistemas de previdência social, que não se limitam a cuidar dos doentes, mas organizam a prevenção sanitária. $A$ princípio, pressupunham uma diferenciação entre assistência social, destinada às classes mais desfavorecidas e baseada no princípio de solidariedade e, portanto, financiada por fundos públicos estatais, e previdência social, mecanismo assecuratório restrito aos trabalhadores. Entretanto, exatamente porque a prevenção sanitária era um dos objetivos do desenvolvimento do Estado, logo se esclarece o conceito de seguridade social, que engloba os subsistemas de assistência, previdência e saúde públicas. Trata-se, portanto, de identificar a responsabilidade a priori do Estado. Assim, quanto aos estilos de vida, verifica-se um grande investimento estatal.

No Brasil, o período que medeia 1950 e 1960, destaca-se a atuação do sanitarismo desenvolvimentista, segundo Labra (1988), suas principais características são: a crítica ao modelo campanhista e à inversão dos termos propostos pelo movimento sanitarista da Primeira República, assim, para o sanitarismo desenvolvimentista o nível de saúde de uma determinada população deve ser mensurada, em primeiro lugar, pelo grau de desenvolvimento econômico do país. Esta concepção predominou durante a III Conferência Nacional de Saúde e pode ser 
vista como precursora das propostas posteriores de reforma do setor de saúde e das teses consagradas durante a VIII Conferência de Saúde (Finkelman, 2002, p. 84).

Com o início do governo de transição de José Sarney, foi desencadeado, no setor da saúde, um conjunto de medidas que tinha por escopo modificar as políticas anteriores que privilegiaram a atenção privatizante em detrimento das ações do setor público (Bertolozzi, Greco, 1996, p. 391). O processo de reforma sanitária impulsionou a realização da VIII Conferência Nacional de Saúde, em 1986, diferente das anteriores com temáticas eminentemente técnicas, trouxe como tema Direito à Saúde, Sistema de Saúde e Financiamento. Os debates que ocorreram na Conferência puseram em destaque as políticas de saúde como questão coletiva, representaram um avanço técnico e um pacto político (Bertolozzi, Greco, 1996,p. 392).

Esse processo de mobilização, construído pelo movimento sanitarista, teve continuidade nos trabalhos de elaboração da nova constituição brasileira e culminou com a aprovação de um capítulo inédito em constituições brasileiras, qual seja, um capítulo dedicado a saúde, espaço em que se refletia, em parte, o pensamento e as conquistas das lutas do movimento sanitarista (Bertolozzi, Greco, 1996, p. 392). Para Dallari (1995, p. 22), no Brasil a incorporação constitucional dos direitos sociais foi sobremaneira lenta. Assim, só tardiamente o Estado e a sociedade brasileira sofreram os efeitos e determinações da consagração positiva dos direitos sociais.

Assim, a Constituição Federal de 1988 foi a primeira Constituição brasileira a consagrar o direito à saúde como direito fundamental. Para Silva (1996, p. 298), é espantoso como um bem extraordinariamente relevante à vida humana só agora é elevado à condição de direito fundamental do homem.

A ideia de direito a saúde exige do intérprete/aplicador do direito à saúde uma análise sistemática do texto constitucional, garantindo sua vinculação imprescindível à noção de bem-estar tratada pela Organização Mundial de Saúde. Sendo assim, Carvalho (2003, p. 24) anota que

Para a sua realização, o Texto Constitucional dispõe, dentro da ordem social, os contornos da seguridade social, na qual são englobadas ações destinadas a assegurar o direito à saúde, financiadas por toda a sociedade, de forma direta ou indireta (art, 194). Essas ações são concretizadas mediante "políticas sociais e econômicas que visem à redução do risco de doença e de outros agravos e ao acesso universal 
e igualitário às ações e serviços para sua promoção, proteção e recuperação" (art. 196) (grifei), e organizadas em um sistema integral e descentralizado denominado Sistema Único de Saúde (SUS) (art. 198). Incorporou conceitos, princípios e uma nova lógica de organização de saúde.

Assim, só se pode conceber o conceito de saúde numa perspectiva de articulação entre políticas econômicas e sociais. $\mathrm{O}$ direito à saúde tornou-se direito universal, não contributivo, não monetário. Pode-se, inclusive, afirmar que o direito à saúde foi desmercadurizado com a Constituição Federal de 1988, ou seja, deixou de ser resultado de seguro social e passou a ser direito de cidadania.

Deve-se destacar, entretanto, que a seguridade social brasileira, e em especial a saúde, apesar dos princípios constitucionais norteadores, ainda tem caráter regressivo, especialmente quando se põem em relevo as fontes de financiamento. $O$ artigo 195 da Constituição Federal de 1988 definiu que os recursos da seguridade devem ser provenientes de três fontes: orçamento do poder público, contribuições sociais e receita de concursos de prognósticos. As contribuições sociais são responsabilidade dos empregadores e trabalhadores.

Entende-se que a ampliação e diversificação das fontes foram estratégias necessárias e coerentes para garantir a expansão dos direitos sociais, bem como para permitir a instituição de um sistema amplo e sustentável de seguridade social, assim ressalta-se a logicidade de inclusão no financiamento da seguridade social o orçamento público e a criação de novas contribuições sociais sobre o faturamento e o lucro. No entanto como afirmam Behring e Boschetti,

Essa diversificação, contudo, não vem se efetivando, e o financiamento ainda incide majoritariamente sobre os trabalhadores, seja pela via da contribuição sobre folha de salários, seja pela via das contribuições sobre o consumo. No período entre 1999 e 2005, as contribuições sociais foram responsáveis, em média, por $91,6 \%$ da arrecadação do orçamento da seguridade social. Entre essas, predominaram a Contribuição dos Empregados e Trabalhadores para a Seguridade Social (Cetss) com 57\%, a Confins com 23,7\%, a CSLL com $3,2 \%$ e a CPMF com 3,5\%. Os recursos provenientes de impostos (orçamento fiscal) contribuíram em média com apenas 6,6\% no período (Behring, Boschetti, 2008, p. 172).

A Constituição Federal de 1988 elevou os serviços e ações de saúde à categoria de relevância pública, com todas às consequências de sua essencialidade. A saúde foi integrada a Seguridade Social. Além disso, a criação do SUS representou uma mudança de paradigma da política de saúde no Brasil. 
A Lei n. 8.080/90, que regula o Sistema Único de Saúde segue um modelo descentralizado, exigindo grande relevância na participação dos municípios. A União trata do caráter mais abrangente da saúde (âmbito nacional), Estados e Distrito Federal, de questões regionais e os Municípios, dos aspectos locais. Portanto, é um sistema sem hierarquia, assumindo características de unidade e cooperação.

O atendimento integral é fruto da universalidade objetiva, sendo que a prioridade para as atividades preventivas, sem prejuízo dos serviços assistenciais, é oriunda da razoabilidade. (Weintraub, 2005, p. 71). Quanto à participação da comunidade, destacam-se os conselhos de saúde, principalmente na esfera municipal. O art. 200 da Constituição Federal apresenta rol de atribuições (não taxativas do SUS). Para Weintraub (2005, p. 72),

Estas diretrizes confirmam o alcance de um conceito amplo de saúde, associado com o equilíbrio biológico, físico, psicológico e social. O sentido estatal preventivo do homem enquanto ser que vive em coletividade, visando dar guarida aos chamados direitos humanos sociais, se manifesta com plenitude dentro dos limites da Seguridade Social constitucional. Os fatores sociais são interdependentes.

Entende-se, por fim, que o direito à saúde, em âmbito constitucional, deve ser analisado sob o prisma da Seguridade Social. Assim, analisar a saúde fora do contexto dos demais direitos fundamentais sociais, em especial os de seguridade, impossibilita uma compreensão plena do direito à saúde. No entanto, cabe destacar que, para Gerschman, diante desse desenho constitucional na saúde,

(...) o principal paradoxo é que o Sistema Único de Saúde, fundado nos princípios universais de universalidade, equidade, integralidade das ações, regionalização, hierarquização, descentralização, participação dos cidadãos e complementaridade do setor privado, vem sendo minado pela péssima qualidade dos serviços, pela falta de recursos, pela ampliação dos esquemas provados que sugam os recursos públicos e pela instabilidade no financiamento (COHN, 1999; Piola, 2001; Nunes, 2001). A proposta de privatização passiva (Draibe, 1990) ou de uma "democracia inconclusa" (Gerschman, 1995).

Por fim, embora, entenda-se que, indiscutivelmente, a Constituição Federal de 1988 tenha representado um grande avanço no padrão de proteção social adotado no Brasil e que essas normas projetem e determinem mudança de paradigmas, deve-se considerar que a passagem do modelo meritocrático-particularista para o modelo institucional-redistributivo exige que Poder Público assuma de forma séria e responsável a sua condição principal ator na condução normativa e de políticas públicas mais equitativas e universais. 


\section{Considerações finais}

Indiscutivelmente, a Constituição Federal de 1988 representou um grande avanço no padrão de proteção social adotado no Brasil. As normas constitucionais projetaram e exigiram uma mudança de paradigma que saiu de um modelo meritocrático-particularista para o modelo institucional-redistributivo, ou seja, um caminho em direção a uma forma mais universalista e igualitária de organização da proteção social no país, em especial a proteção do direito à saúde.

Percebe-se que a Constituição Federal introduziu o caráter redistributivo das políticas sociais (não apenas filantrópico ou distributivo), além de ter exigido do Estado maior grau de responsabilidade pública para regulação, produção e implementação de políticas de proteção social. A grande mudança se afigura na ampliação e na extensão dos direito sociais, o que provocou um maior comprometimento do Estado e da sociedade em geral com o financiamento de todo o sistema de proteção social.

A compreensão da Seguridade Social no Brasil somente torna-se completa e eficaz na medida em que se analisa o contexto de formação do processo da Reforma Sanitária, em especial o período da ditadura militar.

A análise da configuração das expressões da saúde na ditadura militar permitiu compreender o processo de mudança do paradigma da saúde como caridade ou filantropia para a configuração do direito à saúde como elemento fundamental à ideia de cidadania. Demonstrou-se que a Constituição Federal de 1988 é um marco no avanço democrático na formação histórica da sociedade brasileira, exatamente por evidenciar a pluralidade e participação de diferentes atores sociais, razão pela qual os direitos sociais apresentam-se como tessitura normativa para a concretização do direito à saúde na sociedade.

Demonstrou-se que a ideia de que o completo bem-estar (físico, social e mental) do povo está diretamente vinculado às opções dos governos e que a forma de alcançar as metas traçadas pela Constituição Federal e pelo Sistema Único de Saúde perpassam pelo processo de redemocratização da sociedade brasileira e pela efetiva participação popular nos espaços configurados constitucionalmente.

Foi essencial a ampliação do conceito de seguridade social na Constituição Federal de 1988, com a incorporação de concepções e ações relativas à previdência social, à saúde e assistência social. Destaque-se que os princípios da universalidade da cobertura e do atendimento são os indicadores mais significativos da mudança de 
paradigma da concepção de direito à saúde no Brasil. Com a Constituição Federal de 1988 garantiu-se o acesso igualitário a toda população, o atendimento integral (em todos os níveis de complexidade das enfermidades), a priorização de atividades preventivas e a participação da comunidade na definição da própria política de saúde.

Por diversos critérios, pode-se julgar o inegável avanço do sistema de direitos sociais consagrados na Constituição Federal de 1988. No entanto, sua concretização dependerá de diferentes variáveis, desde a aplicabilidade imediata dos direitos sociais ali consagrados, da necessária produção legislativa infraconstitucional clara e coerente em consonância com o sentido do texto constitucional e, principalmente, da disponibilidade de recursos para um real financiamento, como prioridade de governo, para as políticas de corte social.

\section{Referências}

BOBBIO, Norberto. A era dos direitos. 8. ed. Rio de Janeiro: Campus, 1992.

BRAVO, Maria Inês Souza. Política de saúde no Brasil. Disponível em: http://www.saude.mt.gov.br/upload/documento/16/politica-de-saude-no-brasil-pormaria-ines-souza-bravo-[16-200511-SES-MT].pdf

BEHRING, Elaine Rossetti e BOSCHETTI, Ivanete. Política social: fundamentos e história. 4. ed. São Paulo: Cortez, 2008.

BERTOLOZZI, Maria Rita e GRECO, Rosangela Maria. As políticas de saúde no Brasil: reconstrução histórica e perspectivas atuais. Revista da Escola de Enfermagem da USP, São Paulo, 30(3):380-398, 1996.

CARVALHO, Mariana Siqueira de. A saúde como direito social fundamental na Constituição Federal de 1988. Revista de Direito Sanitário, São Paulo, 4(2):15-31, 2013.

DALLARI, Sueli Gandolf. Os Estados brasileiros e o direito à saúde. São Paulo: Hucitec, 1995.

FALEIROS, Vicente de Paula. Natureza e desenvolvimento das políticas sociais no Brasil. Política Social - Módulo 3. Programa de Capacitação Continuada para Assistentes Sociais. Brasília: CFESS/ABEPSS/CEAD-UnB, 2000.

FINKELMAN, Jacobo (org.). Caminhos da saúde no Brasil [online]. Rio de Janeiro: Editora FIOCRUZ, 2002.

GIOVANNI, Geraldo di. Sistema de proteção social: uma introdução conceitual. In: OLIVEIRA, Marco Aurélio de (org.). Reforma do Estado e políticas de emprego no Brasil. Campinas, São Paulo : UNICAMP, IE, 1998.

IBRAHIM, Fábio Zambitte. Curso de Direito Previdenciário. 16. ed. Rio de Janeiro: Impetus, 2011.

MARTINS, Sérgio Pinto. Direito da seguridade social. 17. ed. São Paulo: Atlas, 2002. 
Anais dos III Congresso Iberoamericano de Direito Sanitário / II Congresso Brasileiro de Direito Sanitário

POLIGNANO, Marcos Vinícius. História das políticas de saúde no Brasil: uma

$\begin{array}{ll}\text { pequena revisão. } & \text { Disponível } \\ \text { http://www.medicina.ufmg.br/internatorural/arquivos/mimeo-23p.pdf }\end{array}$

em:

RIZOTTI, Maria Luiza Amaral. A construção do sistema de proteção social no Brasil: avanços e retrocessos na legislação social. Disponível em: http://sisnet.aduaneiras.com.br/lex/doutrinas/arquivos/construcao.pdf

SILVA, José Afonso da. Curso de direito constitucional positivo. 11 ed. São Paulo: Malheiros, 1996.

TAVARES, Maria da Conceição e FIORI, José Luis. (Des) ajuste global e modernização conservadora. Rio de Janeiro: Paz e Terra, 1993.

WEINTRAUB. Arthur Bragança de Vasconcellos. Direito à saúde intrínseco ao campo da seguridade social. Revista de Direito Sanitário, São Paulo, 6(1/2/3):62-72, 2005. 